EINZELAUSGABE

\title{
THE NUBIAN TEXTS OF THE CHRISTIAN PERIOD
}

EDITED BY

\section{F. LL. GRIFFITH OXFORD}

AUS DEN ABHANDLUNGEN DER KONIGL. PREUSS. AKADEMLE DER WISSENSCHAFTEN. JAHRGANG 1913. PHL.-HIST. ClaSSE. Nr. 8

MIT 3 TAFELN

\section{BERLIN 1913}

VERLAG DER KONIGL. AKADEMIE DER WISSENSCHAFTEN

IN COMMISSION BEI GEORG REIMIER 
Vorgelegt in der Sitzung der phil.-hist. Klasse am 3. Juli 1913.

Zum Druck eingereicht am gleichen Tage, ausgegeben am 30. Dezember 1913. 